\title{
Variability of clinical practice decisions on Latin American mobile medical service trips (MSTs)
}

\author{
Christopher Dainton ${ }^{1}$, Charlene H Chu ${ }^{2}$, Henry Lin ${ }^{3}$, Lawrence C Loh ${ }^{4}$ \\ ${ }^{1}$ Michael G. DeGroote - School of Medicine, McMaster University, Hamilton, Canada, ${ }^{2}$ Medical Service Trip Inc., Toronto, Canada, ${ }^{3}$ Department of \\ Pediatrics, University of Pennsylvania, Pennsylvania, USA, ${ }^{4}$ The 53rd Week, Philadelphia, Pennsylvania, USA \\ Keywords: global health \\ https://doi.org/10.29392/joghr.3.e2019034
}

\section{Journal of Global Health Reports}

Vol. 3, 2019

\begin{abstract}
Background
Short-term medical service trips (MSTs) are increasing in popularity, but there is scant evidence evaluating the working competence of volunteer clinicians. Challenges to providing consistent high-quality care include cultural and language barriers, the frequent absence of confirmatory diagnostic tests, and a lack of context-appropriate best practice guidelines.
\end{abstract}

\section{Methods}

A questionnaire using case vignettes was used to compare the management strategies of volunteer clinicians for five of the most common diagnoses seen on MSTs in Latin America and the Caribbean (LAC). North American MST-sending organizations were emailed through a publicly-available database of MSTs. Those who consented to participate were sent the link to a questionnaire based in either a LAC context, or a control version based in the context of a North American clinic.

\begin{abstract}
Results
There were 24 completed responses to the LAC survey and 13 completed responses to the control questionnaire. For dyspepsia, clinicians commonly selected lifestyle interventions and treatment with either an antacid, $\mathrm{H} 2$ antagonist, or proton pump inhibitor (PPI). For acute diarrhea, those completing the LAC context survey were significantly more likely to suggest albendazole $\left({ }^{*} \mathrm{P}=* 0.004\right)$ and trended towards suggesting metronidazole $\left({ }^{*} \mathrm{P}=* 0.117\right)$ and zinc $\left({ }^{*} \mathrm{P}={ }^{*} 0.394\right)$ more frequently. For URI, clinicians commonly suggested acetaminophen or ibuprofen, and less commonly suggested a saline nasal spray. Those responding to the LAC context survey were significantly less likely to recommend cough drops ( $\left.{ }^{*} \mathrm{P}={ }^{*} 0.036\right)$, and significantly more likely to recommend antibiotics $(* \mathrm{P}=* 0.035)$. For vaginal discharge, clinicians commonly suggested empiric treatment for bacterial vaginosis with metronidazole, and those responding to the LAC context survey were more likely to recommend empiric antibiotic treatment $\left({ }^{*} \mathrm{P}=* 0.175\right)$ and advice regarding prevention $\left({ }^{*} \mathrm{P}=* 0.149\right)$ of sexually transmitted infection. For undifferentiated pruritus, clinicians commonly suggested symptomatic treatment with hydrocortisone cream and moisturizing lotion, and those responding to the control questionnaire were significantly more likely to recommend scabicides ( $\left.\mathrm{*} P={ }^{*} 0.039\right)$.
\end{abstract}

\section{Conclusions}

The treatment decisions of MST clinicians for common diagnoses are often highly variable, highlighting a need for increased attention to pre-departure training, and context-appropriate guidelines for best clinical practice.

There is scant evidence to support the clinical outcomes and lasting impacts of Western-led primary care medical service trips (MSTs) in Latin America and the Caribbean (LAC). ${ }^{1}$ MSTs involve North American clinician volunteers from a variety of professional backgrounds and experience levels, who provide direct clinical care in host communities in LAC for periods of often two weeks or less ${ }^{2}$. Their activities are supported by non-governmental organizations (NGOs) operating in developing countries, as well as local health authorities, international institutions, and the private sector. ${ }^{2,3}$ While such trips are increasing in popularity, ${ }^{4}$ existing literature has not evaluated the ability of these volunteer clinicians to manage common symptoms in such unfamiliar and low resource environments.

Symptoms encountered on MSTs in LAC often mirror those encountered in the developed world, and largely consist of gastrointestinal complaints, upper respiratory infections, dermatologic complaints, and gynecologic complaints. $^{5,6}$ It is unclear, however, whether best practice guidelines commonly used in North America are applicable in remote settings in LAC. Factors limiting the transferability of guidelines include the differences in infectious disease epidemiology in LAC, where an increased prevalence of bacterial, parasitic, and fungal etiology might alter ideal pharmacologic management. Language barriers and cultural differences also alter how patients experience and de- 
scribe their symptoms to the clinician and therefore influence the accuracy of clinical assessments. Compounded by the absence of confirmatory laboratory investigations, imaging, and context-specific practice guidelines to aid volunteer clinicians in their management decisions, ${ }^{7}$ clinicians may develop their own heuristics to manage common symptoms, which may not be based on sound evidence. Without guidance from local providers, the risk is that clinical decisions and diagnoses made by MST practitioners can be unreliable or inappropriate to the practice context.

The purpose of this pilot study was to identify and determine the degree of variability in clinical decision making by North American clinicians on MSTs in LAC. As the first study to attempt to fill this knowledge gap, our results will generate baseline exploratory knowledge about the working competence of practitioners who work on MSTs. This can serve as a basis for the development of training, guidelines and recommendations, in addition to targeted educational interventions for clinicians to ensure appropriate management of symptomology that is commonly treated in LAC, and ultimately, improve quality of care for patients.

\section{METHODS}

\section{DESIGN}

A cross-sectional questionnaire featuring case vignettes was electronically distributed to clinicians (physicians, nurse practitioners, osteopathic physicians, physician assistants) who have participated in MSTs in LAC. The psychiatric literature has commonly used case vignettes as an inexpensive method to determine the reliability of diagnoses contained in the Diagnostic and Statistical Manual (DSM), by minimizing confounders such as variations in clinician interviewing style and inconsistent symptom reports by patients. In this study, similar case vignettes were designed to challenge MST clinicians to provide a management plan for common primary care symptoms.

A control version of the case vignettes, set in a North American clinic setting, was used to account for the acceptable degree of variability in clinical practice that would be seen in resource-rich settings. In comparing these vignettes to an identical set taking place on an MST in LAC, we hypothesized that there would be a higher variability in clinician treatment decisions in the MST context. Such lack of consistency might indicate either diagnostic uncertainty, inadequate evidence favouring one treatment, or inadequate provider training. Methodologically, if clinicians do not consistently arrive at similar management decisions for common symptoms, it would suggest the need to develop decision support tools or practice guidelines with strict case definitions.

\section{QUESTIONNAIRE DEVELOPMENT}

Five hypothetical clinical scenarios (dyspepsia, acute diarrhea, upper respiratory infection, vaginal discharge, and pruritus) were developed to assess decision making by volunteer clinicians (Online Supplementary Document(Online Supplementary Document)). Each case contained only the limited clinical information that would realistically be available to the clinician. Multiple choice options that were agreed upon by investigator consensus were listed for each scenario, which aimed to represent the most common clinical management strategies. Efforts were made to ensure that all management options represented either a different aspect of the symptomology, an escalation of treatment, or a different underlying diagnosis. For example, providing a combination of antibiotics that would be expected to presumptively treat sexually transmitted infection were grouped together as one option, and an antibiotic that would be expected to treat bacterial vaginosis as a separate option. Each question included an option for referral to a partner hospital equipped with higher level diagnostic and treatment capacity. In the absence of referral, it was assumed that the follow-up interval was approximately two months, the interval between MST visits for one of the largest MST sending organizations. ${ }^{2}$

The LAC version of the questionnaire was then piloted among a convenience sample of 20 physicians. Participants in the pilot were asked to assess the clarity of each case vignette and the appropriateness of the management options. Participants could select as many appropriate responses as they felt reasonable and were encouraged to write-in responses and provide rationale for their management choices. Participants were timed on completion of the questionnaire to ensure an average completion time of no longer than 15 minutes, to maximize questionnaire completion, and minimize degeneration of response quality due to respondent fatigue. During this pilot exercise, a Cronbach alpha was also calculated at this point $(0.87)$ to assess internal consistency of questions. Similar write-in responses by two or more pilot respondents were assessed for inclusion in the questionnaire by the investigators. In two of the vignettes the multiple-choice options were expanded to include one additional selection.

Two versions of the questionnaire were developed, with identical case vignettes. The preamble of one questionnaire version indicated that the scenarios took place in an MST setting in LAC, while the control version indicated that the scenarios took place in North America. The demographics section of the questionnaire collected: gender, professional designation, years of clinical experience, country of medical training, and information on previous MST experience including type of care provided, clinical setting, diagnostic resources available, and overall comfort level with clinical decision making on an MST.

\section{PARTICIPANTS AND SAMPLING}

Respondents were included in the analysis if they were: clinicians (i.e. medical doctors, doctors of osteopathy, nurse practitioners, or physician assistants) with a licence to practice in Canada or the United States and had previous involvement in an MST in LAC. Students enrolled in a professional faculty (eg, medical students) were excluded. Enrollment was limited to North American clinicians, since their medical training and practice experience is likely to be comparable, and to those whose experience includes MSTs in LAC, where experiences and epidemiology are likely to be comparable.

The publicly available database at medicalservicetrip.com was used to identify MSTs operating in LAC. Organizations were invited to participate in the study by telephone or email using a standard script, and a Fluid Survey questionnaire link was sent to those who agreed, with instructions to forward the link to their affiliated clinicians. The questionnaire link was also shared on Twitter every two weeks for six months beginning on February 1, 2015, alternating between each version of the questionnaire, and using the hashtags: "medicalmission", "medicalmissions", "medicalservice", "medicalbrigade", "medicalbrigades", and "globalhealth". Once an organization consented to participate in the study, a member of the research team not in- 
volved with data collection (CC) used a computerized random number generator to determine whether that organization received the link to the LAC or control version of the questionnaire.

Ethics approval was obtained through the University of Toronto Ethics Board (protocol 29840.)

\section{STATISTICAL ANALYSIS}

The primary outcome of interest was the difference in clinical management choices between LAC scenario respondents and control scenario respondents. STATA was used to aggregate demographic information for all respondents and analyse data from the multiple response questionnaire. Fisher's exact test was used to compare the characteristics of respondents to each version of the survey. A Chi squared test was used to determine whether differences between scenarios in the proportion of clinicians selecting each option were statistically significant $(P<0.05)$.

\section{RESULTS}

Eighty-one NGOs were contacted between February 1, 2015 and July 31, 2016. Twenty-nine organizations (36\%) agreed to participate in the study. In total, there were 24 completed responses to the LAC survey and 13 completed responses to the control survey. The characteristics of all respondents for the LAC and control surveys are described in Table 1, and the characteristics of the organizations are described in Table 2.

\section{DYSPEPSIA SCENARIO}

Responses to the uncomplicated dyspepsia clinical scenario are shown in Table 3 . In both scenarios, clinicians commonly selected lifestyle interventions $\left({ }^{*} \mathrm{P}=* 0.140\right)$, as well as treatment with either an antacid, $\mathrm{H} 2$ antagonist, or proton pump inhibitor (PPI) $\left({ }^{*} \mathrm{P}={ }^{*} 0.538\right)$. Four respondents (16.67\%) suggested that albendazole would be appropriate treatment in the context of an MST in LAC, while none suggested it in the control. Referrals for imaging or endoscopy were uncommon $\left({ }^{*} \mathrm{P}={ }^{*} 0.351\right)$, as was empiric antibiotic treatment for $\mathrm{H}$. pylori related peptic ulcer disease (" $\mathrm{P}=* 1.000)$.

\section{ACUTE DIARRHEA SCENARIO}

Responses to the uncomplicated acute diarrhea clinical scenario are shown in Table 4 . In both scenarios, clinicians commonly selected oral rehydration solutions ( $\left({ }^{*} \mathrm{P}={ }^{*} 0.351\right)$ and declined to use antibiotics $\left({ }^{*} \mathrm{P}={ }^{*} 1.000\right)$, antiemetics $\left({ }^{*} \mathrm{P}={ }^{*} 0.278\right)$, or antidiarrheal medication $\left({ }^{*} \mathrm{P}={ }^{*} 0.117\right)$. Clinicians completing the LAC context survey were significantly more likely than those in the control to suggest albendazole $\left({ }^{*} \mathrm{P}={ }^{*} 0.004\right)$ and trended towards suggesting metronidazole $\left({ }^{*} \mathrm{P}={ }^{*} 0.117\right)$ and zinc $\left({ }^{*} \mathrm{P}={ }^{*} 0.394\right)$ more frequently but were significantly less likely to order stool cultures $\left({ }^{*} \mathrm{P}={ }^{*} 0.004\right)$.

\section{UPPER RESPIRATORY INFECTION (URI) SCENARIO}

Responses to the uncomplicated URI clinical scenario are shown in Table 5 . In both scenarios, clinicians commonly suggested acetaminophen or ibuprofen $\left({ }^{*} \mathrm{P}={ }^{*} 0.383\right)$, and less commonly suggested a saline nasal spray ( $\left.\mathrm{P}={ }^{*} 0.999\right)$. Those responding to the LAC context survey were significantly less likely to recommend cough drops than those in the control $\left({ }^{*} \mathrm{P}={ }^{*} 0.036\right)$, and significantly more likely to recommend antibiotics $\left({ }^{*} \mathrm{P}={ }^{*} 0.035\right)$. There were more referrals for either chest $\mathrm{x}$-ray $\left({ }^{*} \mathrm{P}={ }^{*} 0.037\right)$ or laboratory investigations $\left({ }^{*} \mathrm{P}={ }^{*} 0.117\right)$ by respondents answering the control questionnaire.

\section{VAGINAL DISCHARGE SCENARIO}

Responses to the undifferentiated vaginal discharge clinical scenario are shown in Table 6. In both scenarios, clinicians commonly suggested empiric treatment for bacterial vaginosis with metronidazole ( $\left.{ }^{*} \mathrm{P}={ }^{*} 0.999\right)$. Those responding to the LAC context survey, however, were more likely than those in the control to recommend empiric treatment for sexually transmitted infection (STI) with dual antibiotics $\left({ }^{*} \mathrm{P}={ }^{*} 0.175\right)$, and more likely to provide advice regarding prevention of STIs (* $\mathrm{P}=* 0.149)$, although not significantly so. Presumptive treatment with ciprofloxacin or fluconazole for urinary tract infection or vaginal candidiasis respectively was rare in both groups $\left({ }^{*} \mathrm{P}=* 0.253\right.$ for ciprofloxacin, ${ }^{*} \mathrm{P}={ }^{*} 0.307$ for fluconazole).

\section{UNDIFFERENTIATED PRURITUS SCENARIO}

Responses to the undifferentiated pruritus clinical scenario are shown in Table 7. In both scenarios, clinicians suggested symptomatic treatment with hydrocortisone cream and moisturizing lotion at similar rates $\left({ }^{*} \mathrm{P}={ }^{*} 0.734\right.$ for hydrocortisone, ${ }^{*} \mathrm{P}={ }^{*} 0.489$ for moisturizing lotion). Those responding to the control questionnaire, however, were more likely to treat symptoms with an antihistamine $\left({ }^{*} \mathrm{P}={ }^{*} 0.082\right)$, although not significantly so, while those responding in the LAC context were significantly more likely to recommend scabicides like permethrin or ivermectin $\left({ }^{*} \mathrm{P}={ }^{*} 0.039\right)$.

\section{DISCUSSION}

The findings of this study confirm our hypothesis that clinicians alter their approach to common primary care symptoms in the context of a resource-limited MST, and that their clinical management decisions are highly variable. The strengths of this study include its use of a control scenario, to account for the natural variability of decisionmaking that might be expected of primary care clinicians, even when practicing in their presumed areas of competency. Furthermore, the participants in the study were seasoned clinicians with an average of 20-years clinical experience, which implies that the significant results obtained in this study might even be an underestimate of true differences in a pool of clinicians that includes those with less experience. The goal of this study was to determine the consistency of decisions with simple scenarios that presented no diagnostic dilemmas, and accordingly, few respondents proposed referrals of patients to a tertiary care centre. This underlines the role of the primary care practitioner as a manager of scarce resources, as well as the acknowledgement of the lack of transportation and access to additional care in an MST context. The following sections compare respondents' most commonly selected management practices to international practice guidelines, with attention paid to potential reasons for the observed differences between the two settings.

\section{UNCOMPLICATED DYSPEPSIA}

Respondents in both the LAC context and the control sug- 
Table 1. Demographic characteristics and Fisher's exact test p-coefficients for respondents to a questionnaire assessing clinical management decisions for five hypothetical scenarios set in either a Latin American medical service trip or North American context

\begin{tabular}{|c|c|c|c|c|}
\hline & & Latin American context & Control/North American context & $P$-values \\
\hline \multirow{2}{*}{ Gender } & Male & $15(62.5 \%)$ & $7(53.9 \%)$ & \multirow[t]{2}{*}{$P=0.730$} \\
\hline & Female & $9(37.5 \%)$ & $6(46.2 \%)$ & \\
\hline $\begin{array}{l}\text { Average years of } \\
\text { active practice }\end{array}$ & & 21.02 years & 21.67 years & - \\
\hline \multirow{2}{*}{$\begin{array}{l}\text { Professional } \\
\text { designation }\end{array}$} & Medical doctor & $19(79.2 \%)$ & $9(69.2 \%)$ & \multirow[t]{2}{*}{$P=0.691$} \\
\hline & Others & $\begin{array}{l}5(20.8 \%): 3 \text { Nurse } \\
\text { Practitioners }\end{array}$ & $\begin{array}{l}4(30.8 \%): 3 \text { Doctor of } \\
\text { Osteopathy }\end{array}$ & \\
\hline \multirow{6}{*}{ Clinical expertise } & $\begin{array}{l}\text { Family } \\
\text { medicine }\end{array}$ & $11(45.8 \%)$ & $5(38.5 \%)$ & \multirow[t]{6}{*}{$P=0.098$} \\
\hline & $\begin{array}{l}\text { Pediatric } \\
\text { Medicine }\end{array}$ & $5(16.7 \%)$ & $1(7.7 \%)$ & \\
\hline & $\begin{array}{l}\text { Internal } \\
\text { Medicine }\end{array}$ & $1(4.2 \%)$ & $3(23.1 \%)$ & \\
\hline & $\begin{array}{l}\text { Emergency } \\
\text { Medicine }\end{array}$ & $9(33.3 \%)$ & $2(15.4 \%)$ & \\
\hline & $\begin{array}{l}\text { Non-primary } \\
\text { care specialty }\end{array}$ & $\begin{array}{l}4(16.67 \%) \text { : State prison, } \\
\text { pulmonary, hospital } \\
\text { pharmacy, general surgery }\end{array}$ & $\begin{array}{l}\text { 4(30.8\%): Immunology, trauma } \\
\text { surgery, gynecology, vascular } \\
\text { and general surgery }\end{array}$ & \\
\hline & $\begin{array}{l}\text { Additional } \\
\text { global health } \\
\text { training }\end{array}$ & $0(0.0 \%)$ & $2(15.4 \%)$ & \\
\hline \multirow{4}{*}{$\begin{array}{l}\text { Country of medical } \\
\text { training }\end{array}$} & United States & $12(50.0 \%)$ & $11(84.6 \%)$ & \multirow[t]{4}{*}{$P=0.262$} \\
\hline & Canada & $6(25.0 \%)$ & $2(15.4 \%)$ & \\
\hline & & 6 (25.0\%): Cuba, France & & \\
\hline & Others & $\begin{array}{l}\text { ( } 2 \text { ), Zimbabwe, } \\
\text { Mexico }\end{array}$ & 1 (7.7\%): United Kingdom & \\
\hline \multirow{5}{*}{$\begin{array}{l}\text { Comfort level with } \\
\text { practice in resource- } \\
\text { limited settings }\end{array}$} & $\begin{array}{l}\text { Very } \\
\text { comfortable }\end{array}$ & $7(29.2 \%)$ & $0(0.0 \%)$ & \multirow[t]{5}{*}{$P=0.095$} \\
\hline & Comfortable & $12(50.0 \%)$ & $8(61.5 \%)$ & \\
\hline & Neutral & $2(8.3 \%)$ & $1(7.7 \%)$ & \\
\hline & Uncomfortable & $1(4.2 \%)$ & $3(23.1 \%)$ & \\
\hline & $\begin{array}{l}\text { Very } \\
\text { uncomfortable }\end{array}$ & 2 (8.3\%) & $1(7.7 \%)$ & \\
\hline \multirow{3}{*}{$\begin{array}{l}\text { Context of most } \\
\text { recent MST }\end{array}$} & $\begin{array}{l}\text { Informal or } \\
\text { mobile clinic }\end{array}$ & $18(75.0 \%)$ & $12(92.3 \%)$ & \multirow[t]{3}{*}{$P=0.563$} \\
\hline & $\begin{array}{l}\text { Permanent } \\
\text { clinic }\end{array}$ & $3(12.50 \%)$ & $1(7.7 \%)$ & \\
\hline & No response & $3(12.50 \%)$ & 0 & \\
\hline $\begin{array}{l}\text { Practicing primary } \\
\text { care }\end{array}$ & & $17(70.8 \%)$ & $9(69.2 \%)$ & $P=0.999$ \\
\hline \multirow{6}{*}{$\begin{array}{l}\text { Diagnostic resources } \\
\text { available on most } \\
\text { recent MST }\end{array}$} & $\begin{array}{l}\text { Point of care } \\
\text { testing }\end{array}$ & 20(83.3\%) & $10(76.9 \%)$ & \multirow[t]{6}{*}{$P=0.118$} \\
\hline & Full laboratory & 0 (0.0\%) & $1(7.7 \%)$ & \\
\hline & X-ray & $0(0.0 \%$ & $1(7.7 \%)$ & \\
\hline & Ultrasound & $0(0.0 \%)$ & $2(15.4 \%)$ & \\
\hline & ECG & $1(4.2 \%)$ & $3(23.1)$ & \\
\hline & Others & $3(12.5 \%)$ & $2(15.4 \%)$ & \\
\hline
\end{tabular}

gested management options that were consistent with published recommendations, including lifestyle advice, and treatment with an antacid, histamine-2 receptor antagonist, or PPI, ${ }^{9}$ but some important differences remained. In- 
Table 2. Frequency of medical service trips (MSTs) operated by non-government organizations (NGOs) responding to Latin America and the Caribbean (LAC) and control versions of clinical practice survey

\begin{tabular}{|c|c|c|c|c|c|}
\hline & \multicolumn{2}{|c|}{ LAC survey } & \multicolumn{2}{|c|}{ Control survey } & \multirow[t]{2}{*}{$\begin{array}{l}\text { Total } \\
\text { responses }\end{array}$} \\
\hline & $\begin{array}{l}\text { Number of } \\
\text { NGOs }\end{array}$ & $\begin{array}{l}\text { Number of } \\
\text { responses }\end{array}$ & $\begin{array}{l}\text { Number of } \\
\text { NGOs }\end{array}$ & $\begin{array}{l}\text { Number of } \\
\text { responses }\end{array}$ & \\
\hline $\begin{array}{l}\text { Organizations } \\
\text { receiving link }\end{array}$ & 14 & 21 & 15 & 9 & \\
\hline >12 MSTs per year & 1 & 4 & 0 & 0 & 4 \\
\hline 4-12 MSTs per year & 2 & 5 & 2 & 4 & 9 \\
\hline $\begin{array}{l}3 \text { or fewer MSTs per } \\
\text { year }\end{array}$ & 7 & 12 & 3 & 5 & 17 \\
\hline Social media links & - & 3 & - & 4 & 7 \\
\hline
\end{tabular}

Table 3. Clinical management suggestions for a hypothetical patient presenting with uncomplicated dyspepsia in either a Latin American medical service trip (MST) or North American context ( $\mathrm{n}=37$ )

\begin{tabular}{lccc}
\hline & Latin American context $(\mathrm{n}=24)$ & $\begin{array}{c}\text { Control/Western context } \\
(\mathrm{n}=13)\end{array}$ & $P$-value \\
Lifestyle and dietary intervention & $19(79.2 \%)$ & $13(92.3 \%)$ & $P=0.140$ \\
Calcium or magnesium antacid as need & $12(50.0 \%)$ & $4(30.8 \%)$ & $P=0.315$ \\
Histamine-2 antagonist or proton pump & $15(62.5 \%)$ & $13(100.0 \%)$ & $P=0.015$ \\
inhibitor (PPI) & $21(88.0 \%)$ & $13(100.0 \%)$ & $P=0.538$ \\
Any antacid, histamine-2 antagonist, or PPI & $4(16.7 \%)$ & $0(0.0 \%$ & $P=0.276$ \\
Albendazole & $1(4.2 \%)$ & $1(7.7 \%)$ & $P=0.999$ \\
Metronidazole and amoxicillin & $0(0.0 \%)$ & $1(7.7 \%)$ & $P=0.351$ \\
Referral to hospital for endoscopy & $1(4.2 \%)$ & $1(7.7 \%)$ & $P=0.999$ \\
Referral for abdominal ultrasound & changes) & $1(7.7 \%$; bloodwork) \\
Others & (8.3\%; ultrasound, other lifestyle & \\
\hline
\end{tabular}

Table 4. Clinical management suggestions for a hypothetical patient presenting with uncomplicated acute diarrhea in either a Latin American medical service trip (MST) or North American context $(n=37)$

\begin{tabular}{|c|c|c|c|}
\hline & Latin American context $(n=24)$ & $\begin{array}{l}\text { Western context } \\
\quad(n=13)\end{array}$ & $P$-value \\
\hline $\begin{array}{l}\text { Instructions to mother regarding oral } \\
\text { rehydration solution }\end{array}$ & $24(100.0 \%)$ & $12(92.3 \%)$ & $P=0.351$ \\
\hline Antiemetic as needed & $1(4.2 \%)$ & $2(15.4 \%)$ & $P=0.278$ \\
\hline Antimotility/antidiarrheal agent as needed & $0(0.0 \%)$ & $2(15.4 \%)$ & $P=0.117$ \\
\hline Ciprofloxacin or azithromycin & $2(8.3 \%)$ & $1(7.7 \%)$ & $P=0.999$ \\
\hline Albendazole & $14(58.3 \%)$ & $1(7.7 \%)$ & $P=0.004$ \\
\hline Metronidazole & $7(29.2 \%)$ & $2(15.4 \%)$ & $P=0.117$ \\
\hline Zinc & $5(20.8 \%)$ & $1(7.7 \%)$ & $P=0.394$ \\
\hline $\begin{array}{l}\text { Referral for laboratory investigations and/or } \\
\text { stool culture }\end{array}$ & $1(4.2 \%)$ & $6(46.2 \%)$ & $P=0.004$ \\
\hline Referral to hospital for intravenous rehydration & $0(0.0 \%)$ & $0(0.0 \%)$ & - \\
\hline Others & $\begin{array}{c}3 \text { (15.4\%) (antiparasitic, follow-up, } \\
\text { hydration) }\end{array}$ & $0(0.0 \%)$ & \\
\hline
\end{tabular}

terestingly, clinicians who responded to the LAC context questionnaire occasionally suggested anti-parasitic treat- ment with albendazole. While its relevance as an initial treatment for dyspepsia is questionable, albendazole has 
Table 5. Clinical management suggestions for a hypothetical patient presenting with an uncomplicated URI in either a Latin American medical service trip (MST) or North American context ( $n=37)$

\begin{tabular}{|c|c|c|c|}
\hline & Latin American context $(n=24)$ & Western context $(n=13)$ & $P$-value \\
\hline Cough drops as needed & $7(29.2 \%)$ & $9(69.2 \%)$ & $P=0.036$ \\
\hline $\begin{array}{l}\text { Amoxicillin or macrolide } \\
\text { antibiotic }\end{array}$ & $13(54.2 \%)$ & $2(15.4 \%)$ & $P=0.035$ \\
\hline Salbutamol inhaler as needed & $0(0.0 \%)$ & $0(0.0 \%)$ & - \\
\hline $\begin{array}{l}\text { Ibuprofen or acetaminophen as } \\
\text { needed }\end{array}$ & $18(75.0 \%)$ & $12(92.3 \%)$ & $P=0.383$ \\
\hline Nasal saline spray as needed & $7(29.2 \%)$ & $4(30.8 \%)$ & $P=0.999$ \\
\hline Referral for chest radiograph & $0(0.0 \%)$ & $3(23.1 \%)$ & $P=0.037$ \\
\hline $\begin{array}{l}\text { Referral for laboratory } \\
\text { investigations }\end{array}$ & $0(0.0 \%)$ & $2(15.4 \%)$ & $P=0.117$ \\
\hline Others & $\begin{array}{l}2 \text { (15.4\%) (sinusitis treatment, } \\
\text { antihistamine) }\end{array}$ & $\begin{array}{c}3(23.1 \%) \text { (follow up, strep swab, } \\
\text { macrolide) }\end{array}$ & \\
\hline
\end{tabular}

Table 6. Clinical management suggestions for a hypothetical patient presenting with undifferentiated vaginal discharge in either a Latin American medical service trip (MST) or North American context $(\mathrm{n}=37)$

\begin{tabular}{lccc}
\hline & $\begin{array}{c}\text { Latin } \\
\text { American context } \\
(\mathbf{n}=24)\end{array}$ & $\begin{array}{c}\text { Western context } \\
(\mathbf{n}=12)\end{array}$ & $P$-value \\
Metronidazole & $13(54.2 \%)$ & $6(46.2 \%)$ & $P=0.999$ \\
Azithromycin and third generation cephalosporin & $16(66.7 \%)$ & $5(38.5 \%)$ & $P=0.175$ \\
Ciprofloxacin & $1(4.2 \%)$ & $2(15.4 \%)$ & $P=0.253$ \\
No treatment & $0(0.0 \%)$ & $1(7.7 \%)$ & $P=0.333$ \\
Treatment for partners & $18(75.0 \%)$ & $6(46.2 \%)$ & $P=0.157$ \\
Advice regarding prevention of sexually transmitted & $22(91.7 \%)$ & $8(61.5 \%)$ & $P=0.149$ \\
infections & $2(8.3 \%)$ & $3(23.1 \%)$ & $P=0.307$ \\
Fluconazole & $0(0.0 \%)$ & $0(0.0 \%)$ & - \\
Referral for pelvic ultrasound & $1(4.2 \%)($ speculum exam) & $0(0.0 \%)$ & \\
Others & & & \\
\hline
\end{tabular}

Table 7. Clinical management suggestions for a hypothetical patient presenting with undifferentiated pruritus in either a Latin American medical service trip (MST) or North American context ( $n=37)$

\begin{tabular}{lccc} 
& Latin American context ( $\mathrm{n}=24)$ & Western context (n=13) & $P$-value \\
Cephalexin or flucloxicillin & $0(0.0 \%)$ & $0(0.0 \%)$ & - \\
Antihistamine as needed & $10(41.7 \%)$ & $9(69.2 \%)$ & $P=0.082$ \\
Ivermectin or permethrin & $18(75.0 \%)$ & $5(38.5 \%)$ & $P=0.039$ \\
Antibiotic ointment & $1(4.2 \%)$ & $0(0.0 \%)$ & $P=0.999$ \\
Fluconazole or clotrimazole & $1(4.2 \%)$ & $0(0.0 \%)$ & $P=0.999$ \\
Hydrocortisone cream & $9(37.5 \%)$ & $4(30.8 \%)$ & $P=0.734$ \\
Moisturizing lotion & $9(37.5 \%)$ & $7(53.8 \%)$ & $P=0.489$ \\
No treatment & $0(0.0 \%)$ & $0(0.0 \%)$ & - \\
Referral to hospital-based & $0(0.0 \%)$ & $2(15.4 \%)$ & \\
dermatologist & $1(4.2 \%)$ (boil clothes and treat & $2(15.4 \%)($ steroid cream, consider \\
Others & siblings) & lice) & \\
\hline
\end{tabular}

been proposed as an option for refractory symptoms that may be caused by hookworm. ${ }^{10}$ Furthermore, treatment 
with antibiotics for $\mathrm{H}$. pylori was not frequently selected in both scenarios, despite the endemicity of the bacteria in $\mathrm{LAC}^{11}$ and its strong association with peptic ulcer disease. $H$. pylori testing is likely cost-prohibitive or inaccessible in a remote MST setting. It is therefore unclear how to balance the benefits of a strict "test and treat" strategy on reducing drug adverse effects and antibiotic resistance, with the possible need to relax such standards to allow for empiric treatment in cases with high clinical suspicion and limited access to testing.

\section{UNCOMPLICATED ACUTE DIARRHEA}

While respondents to both questionnaires commonly recommended oral hydration, which is supported by international guidelines, ${ }^{12}$ responses diverged on other identified treatments. Despite widespread recommendations that zinc be used routinely in the treatment of acute diarrhea in children, ${ }^{9}$ few clinicians selected this option. In contrast, many clinicians selected deworming treatment with albendazole in a LAC setting, despite disagreement in the literature on whether infection with soil transmitted helminths is associated with diarrhea. ${ }^{13}$ While metronidazole was also commonly suggested by respondents, international guidelines recommend empiric amoebiasis treatment with metronidazole only in cases of persistent diarrhea or refractory dysentery. ${ }^{9}$ Likewise, while giardia carriage is common in the developing world and effectively treated by metronidazole, it remains unclear whether the carrier state is associated with an increased incidence of acute diarrhea. ${ }^{10}$ Further clarification and pre-departure training on appropriate management of acute diarrhea may be necessary to avoid both overtreatment and undertreatment.

\section{UNCOMPLICATED URI}

When presented with the simple URI scenario, respondents suggested a range of symptomatic treatments, including acetaminophen or ibuprofen, saline nasal spray, and cough drops. Interestingly, antibiotics were frequently recommended in the LAC context despite the absence of specific indications. One might speculate that this could be related to the limited availability of diagnostic investigations on an MST, as well as the unclear clinical follow-up in remote settings. Clinicians might therefore reason that the consequences of missed diagnosis could be substantial, including the sequelae of untreated pneumonia.

\section{VAGINAL DISCHARGE}

Neither questionnaire scenario provided respondents with the benefit of immediate culture results, and in this context, approximately half of respondents in either group suggested empiric treatment for bacterial vaginosis. Clinicians were more likely to suggest additional immediate treatment for STIs in the LAC setting. This finding might reflect clinician perceptions of a higher incidence of STIs in the LAC context, or a recognition of the limited clinical follow-up available, balanced with the acknowledgment that the morbidity of a missed diagnosis of gonorrhea or chlamydia can include chronic pelvic pain and infertility.

\section{UNDIFFERENTIATED PRURITUS}

When presented with the undifferentiated pruritus scenario, both groups of respondents commonly suggested a variety of symptomatic treatments, including hydrocortisone, an antihistamine, and moisturizing lotion. However, respondents to the LAC context scenario were more likely to suggest empiric treatment for scabies. Given the lack of a characteristic distribution for scabies ${ }^{9}$ described in the scenario, it is unclear whether this represents a tendency towards overtreatment, or an appropriate response to the high prevalence of scabies in areas served by MSTs. ${ }^{6,14}$

\section{LIMITATIONS}

This study has the following limitations. The first is the small sample size and low response rate, common among surveys involving clinicians, which nevertheless limits the conclusions that can be drawn. Bias may also have been introduced by the characteristics of clinicians who have the time and willingness to respond to the survey, as well as organizational structures that are more amenable to such research initiatives. Second, although participants were informed that there were no correct answers and that their responses were anonymous, the use of a self-report measure may still introduce an element of social desirability bias. ${ }^{15,16}$ Third, given the wide range of individual clinician experiences, settings, and circumstances encountered on MSTs in LAC, a baseline level of variability in clinical management could be expected.

\section{CONCLUSIONS AND FUTURE DIRECTIONS}

Even when presented with identical, uncomplicated clinical scenarios, the treatment recommendations of MST clinicians are highly variable. These findings provide further evidence that clinical guidelines development is necessary in conjunction with partners in host countries, as well as context-specific predeparture training to ensure that patients in host communities receive high quality, consistent care. The scenarios used in this exercise may also have future utility in preparing clinicians to participate in MSTs. Prospective participants might undertake the exercise and be advised of their results in assisting them to align their work more appropriately to the context where they will be exposed to.

Correspondence to:

Dr. Christopher Dainton

1002-8 The Esplanade

Toronto

Canada M5E 0A6

Christopher.dainton@gmail.com 


\section{REFERENCES}

1. Sykes KJ. Short-Term Medical Service Trips: A Systematic Review of the Evidence. Am J Public Health. 2014;104(7):e38-e48. doi:10.2105/ajph.2014.3 $\underline{01983}$

2. Lasker JN. Hoping to Help: The Promises and Pitfalls of Global Health Volunteering. Ithaca; London: Cornell University Press; 2016.

3. Norton I, Von Schreeb J, Aitken P, Herard P, Lajolo C. Classification and Minimum Standards for Foreign Medical Teams in Sudden Onset Disasters. Geneva: World Health Organization; 2013.

4. Caldron PH, Impens A, Pavlova M, Groot W. A systematic review of social, economic and diplomatic aspects of short-term medical missions. BMC Health Serv Res. 2015;15(1):380. doi:10.1186/s12913-015-09 $\underline{80-3}$

5. Dainton C, Chu C. Symptom clusters on primary care medical service trips in five regions in Latin America. J Epidemiol Glob Health. 2015;5(3):259-264. doi:10.1016/j.jegh.2014.12.002

6. Martiniuk AL, Manouchehrian M, Negin JA, Zwi AB. Primary Care Provision by Volunteer Medical Brigades in Honduras: A Health Record Review of More Than 2,500 Patients Over Three Years. Int J Health Serv. 2012;42(4):739-753. doi:10.2190/hs.4 2.4.i

7. Dainton C, Chu CH, Lin H, Cherniak W, Loh LC. A protocol to develop practice guidelines for medical service trips. Ann Glob Health. 2016;82(5):678-685. d oi:10.1016/j.aogh.2016.10.001

8. Grove WM, Andreasen NC, McDonald-Scott P, Keller MB, Shapiro RW. Reliability studies of psychiatric diagnosis. Arch Gen Psychiatry. 1981;38(4):408-413. doi:10.1001/archpsyc.1981.0178 0290042004
9. Grouzard V, Rigal J, Sutton M. Clinical Guidelines: Diagnosis and Treatment Manual. Medecins Sans Frontiers; 2016. http://refbooks.msf.org/msf docs/en/ clinical_guide/cg_en.pdf. Accessed January 29, 2017.

10. Levine MM, Kotloff KL, Nataro JP, Muhsen K. The Global Enteric Multicenter Study (GEMS): Impetus, rationale, and genesis. Clin Infect Dis. 2012;55(suppl 4):S215-S224. doi:10.1093/cid/cis761

11. Frenck RW Jr, Clemens J. Helicobacter in the developing world. Microbes Infect. 2003;5(8):705-713. doi:10.1016/s1286-4579(03)0011 $\underline{2-6}$

12. World Health Organization. The Treatment of Diarrhea: A Manual for Physicians and Other Senior Health Workers. http://www.who.int/maternal_child_a dolescent/documents/9241593180/en/. Accessed November 19, 2013.

13. Jacobsen KH, Ribeiro PS, Quist BK, Rydbeck BV. Prevalence of intestinal parasites in young Quichua children in the highlands of rural Ecuador. $J$ Health Popul Nutr. 2007;25:399-405.

14. Hengge UR, Currie BJ, Jäger G, Lupi O, Schwartz RA. Scabies: A ubiquitous neglected skin disease. Lancet Infect Dis. 2006;6(12):769-779. doi:10.1016/s1 473-3099(06)70654-5

15. Podsakoff PM, MacKenzie SB, Lee J-Y, Podsakoff NP. Common method biases in behavioral research: A critical review of the literature and recommended remedies. J Appl Psychol. 2003;88(5):879-903. doi:1 $\underline{0.1037 / 0021-9010.88 .5 .879}$

16. Crowne D, Marlow DP. The Approval Motive: Studies in Evaluative Dependence. New York: Wiley; 1964. 


\section{FIGURES, TABLES, AND SUPPLEMENTARY MATERIALS}

\section{Online Supplementary Document}

Download: https://www.joghr.org/article/11975-variability-of-clinical-practice-decisions-on-latin-american-mobilemedical-service-trips-msts/attachment/29525.pdf 